\title{
Correction to: Pneumatosis cystoides intestinalis induced by the alpha-glucosidase inhibitor complicated from sigmoid volvulus in a diabetic patient
}

\author{
Andrea Police $^{1} \cdot$ Lionel Charre $^{1} \cdot$ Enrico Volpin ${ }^{1} \cdot$ Christos Antonopulos $^{1} \cdot$ Hamdi Braham $^{1} \cdot$ Najib El Arbi $^{1}$ \\ Published online: 30 March 2020 \\ (C) Springer-Verlag GmbH Germany, part of Springer Nature 2020
}

\section{Correction to: International Journal of Colorectal Disease} https://doi.org/10.1007/s00384-020-03549-3

The name and the email information of one of the author on the original published version of this article were presented incorrectly. The author name "Hamdi Brham" with email information Hamdi.brham@ch-simoneveil.fr should have been presented as "Hamdi Braham" with the correct email information, Hamdi.braham@ch-simoneveil.fr.

The original article has been corrected.

The online version of the original article can be found at https://doi.org/ 10.1007/s00384-020-03549-3

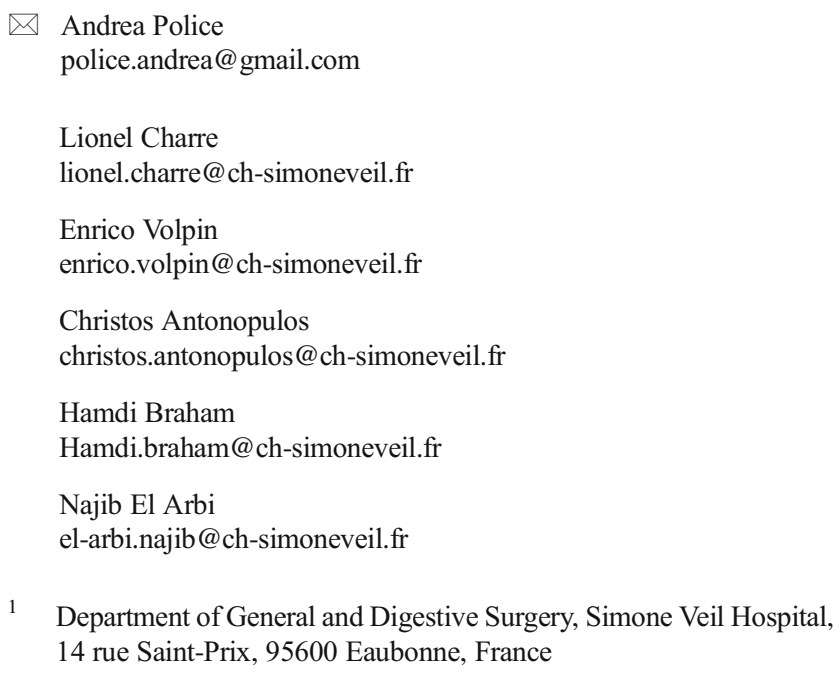

